attributed not only to the action of the rennet, but also, as our papers about to appear will show, to the elaboration of a peptic-like enzyme by certain lactic acid streptococci. Even within the first twenty-four hours of ripening, the amount of subpeptone appearing suggests that associated with the peptic-like action is a tryptic-like action-a conjecture that again in the light of our cultural studies on certain other lactic acid streptococci is not without merit.

Subject to qualification as further data on the nature of specific enzymes may appear, the results of our study show that after the first few hours of ripening, the proteolytic breakdown in the ripening of Kingston cheese is of an associative peptic-trypticlike nature.

This study of nitrogen distribution is one of a series on cheese-ripening which is provided for by a research fund established jointly by the Empire Marketing Board and the University of British Columbia. A detailed account of the experiments will appear shortly in the Journal of Dairy Research, Cambridge.

Blythe A. Eagles.

University of British Columbia,

WIIFRID SADLER.

Vancouver, Canada,

Mar. 27.

\section{Insect Remains in the Gut of a Cobra, Naia tripudians.}

THE accompanying photograph (Fig. 1) shows the remains of insects belonging to three orders, namely, Rhynchota (Heteroptera-Pentatomidæ), Coleoptera, and Hymenoptera (Formicoidea), found in the gut of a cobra, Naia tripudians, brought to us in November 1928. The cobra, which was the black variety with no markings on the back of the hood but with white

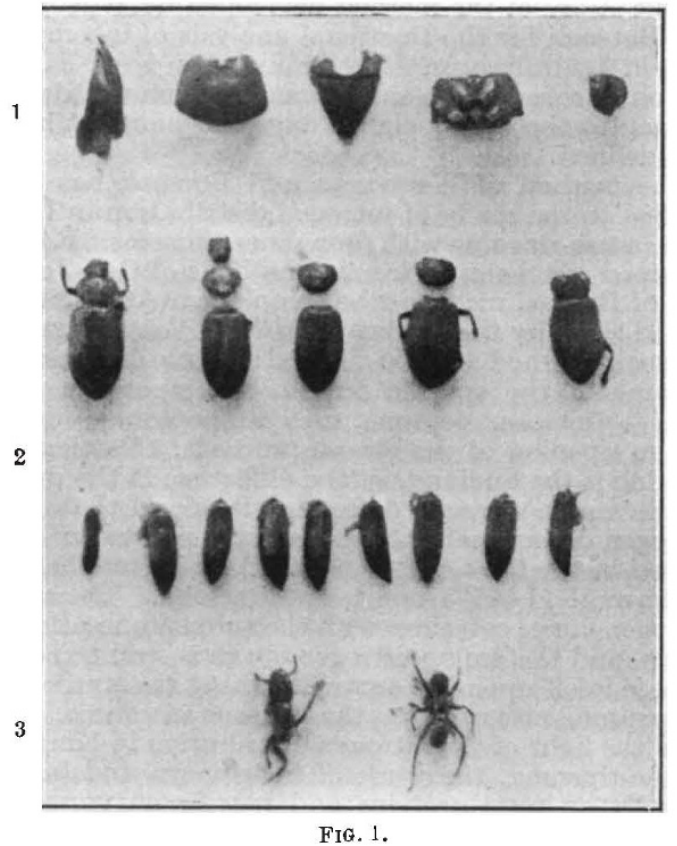

patches on the throat, was captured at Banting, in the vicinity of Kuala Lumpur, Selangor, F.M.S. It was not a large specimen, since it measured only $3 \mathrm{ft} .73$ in. in length.

So far as it has been possible to ascertain, records of insects having been devoured by snakes do not appear to be abundant, the only other two which have come to our notice being that of "a small ruddy beetle" found in the gut of Tropidonotus stolatus (Wall and Evans, Journal Bombay Nat. Hist. Soc., vol. 13) and of a locust (the species not stated) eaten on one occasion by Echis carinata (Wall, id., vol. 18).

The parts of the pentatomid comprise a right hemielytron, pronotum, sternum, scutellum, and pygophor. The ants are ponerines and are capable of inflicting a nasty sting.

We are indebted to Dr. T. A. Buckley, Forest Department, S.S. and F.M.S., for assistance in preparing the photograph.

N. C. E. Mirler.

Department of Agriculture,

Straits Settlements and

Federated Malay States.

\section{The Beginning of the World from the Point of View of Quantum Theory.}

Sir Arthur Eddingron ${ }^{1}$ states that, philosophically, the notion of a beginning of the present order of Nature is repugnant to him. I would rather be inclined to think that the present state of quantum theory suggests a beginning of the world very different from the present order of Nature. Thermodynamical principles from the point of view of quantum theory may be stated as follows : (1) Energy of constant total amount is distributed in discrete quanta. (2) The number of distinct quanta is ever increasing. If we go back in the course of time we must find fewer and fewer quanta, until we find all the energy of the universe packed in a few or even in a unique quantum.

Now, in atomic processes, the notions of space and time are no more than statistical notions; they fade out when applied to individual phenomena involving but a small number of quanta. If the world has begun with a single quantum, the notions of space and time would altogether fail to have any meaning at the beginning; they would only begin to have a sensible meaning when the original quantum had been divided into a sufficient number of quanta. If this suggestion is correct, the beginning of the world happened a little before the beginning of space and time. I think that such a beginning of the world is far enough from the present order of Nature to be not at all repugnant

It may be difficult to follow up the idea in detail as we are not yet able to count the quantum packets in every case. For example, it may be that an atomic nucleus must be counted as a unique quantum, the atomic number acting as a kind of quantum number. If the future development of quantum theory happens to turn in that direction, we could conceive the begin. ning of the universe in the form of a unique atom, the atomic weight of which is the total mass of the universe. This highly unstable atom would divide in smaller and smaller atoms by a kind of super-radioactive process. Some remnant of this process might, according to Sir James Jeans's idea, foster the heat of the stars until our low atomic number atoms allowed life to be possible.

Clearly the initial quantum could not conceal in itself the whole course of evolution; but, according to the principle of indeterminacy, that is not necessary. Our world is now understood to be a world where something really happens; the whole story of the world need not have been written down in the first quantum like a song on the disc of a phonograph. The whole matter of the world must have been present at the beginning, but the story it has to tell may be written step by step. G. LEMAîTRE.

40 rue de Namur, Louvain.

${ }^{1}$ NATURE, Mar, 21, p. 447.

No. 3210, VoL. 127] 